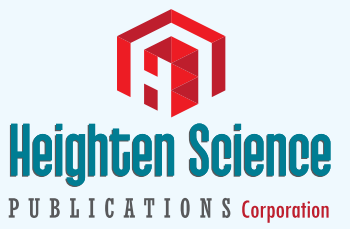

ISSN

2577-1469

\title{
Stem cells in patients with heart failure experience
}

\author{
Benetti Federico ${ }^{1,2 *}$ and Natalia Scialacomo $0^{1,2}$ \\ ${ }^{1}$ Cardiac Surgeons, Department of Surgery, Benetti Foundation Alem 1846 Rosario, Argentina \\ ${ }^{2}$ Regenerative Medicine, Department of Surgery, Benetti Foundation Alem 1846 Rosario, \\ Argentina
}

\begin{abstract}
*Address for Correspondence: Benetti Federico Cardiac surgeons, Regenerative Medicine, Department of Surgery, Benetti Foundation Alem 1846 Rosario, Argentina, Tel: 543415076262 Email: federicobenetti@hotmail.com
\end{abstract}

Submitted: 30 March 2018

Approved: 18 April 2018

Published: 20 April 2018

Copyright: @ 2018 Federico B, et al. This is an open access article distributed under the Creative Commons Attribution License, which permits unrestricted use, distribution, and reproduction in any medium, provided the original work is properly cited.

Keywords: Stem cells in patients with hea failure; Hyperbaric oxygen and angiogenesis in heart failure patients; Treatment of idiopathic myocadiopathy with stem cells; Autologous stem cells in patients with cardiac insufficiency; Embryophetal cells in patients with heart failure

\section{Abstract}

Between 2003 and 2011, 17 patients with heart failure were treated with stem cells as part of our Foundation's Regenerative Medicine program. In several centers and countries 4 with ischemic cardiomyopathy of which 3 were surgically implanted with autologous bone marrow stem cells (ABMSC) plus bypass surgery. One patient was treated with hyperbaric medicine plus bypass surgery. Patients with idiopathic cardiomyopathy were implanted surgically with 2 different types of stem cells. Ten patients were implanted with stem cells derived from human fetuses (HFDSCs) and three patients with autologous bone marrow stem cells (ABMSC). The ejection fractions of the coronary artery bypass graft off pump OPCAB (control group) versus coronary artery bypass group off pump OPCAB plus stem cell transplantation were as followsin the entire serie: preoperative, $30.7 \%+/-2.5 \%$ compared to $29.4 \%+/-3.6 \%$; 1 month, $36.4 \%+/-2.6 \%$ versus $42.1 \%+/-3.5 \%$; 3 months, $36.5 \%$ +/- $3.0 \%$ vs. $45.5 \%+/-2.2 \%$; And 6 months, $37.2 \%+/-3.4 \%$ versus $46.1 \%+/-1.9 \%$ ( $<<0.001)$. The first patient performed at our center in Argentina in this series is alive and asymptomatic 15 years after implantation, and the rest of this series we do not have current data. A patient without visible vessels in the anterior wall of the left ventricle was treated with 18 hyperbaric chamber sections from one hour at 1.4 AT. After creating angiogenesis, the patient was operated on receiving 2 grafts (mammary and venous) without extracorporeal circulation in the anterior descending artery and diagonal artery. The preoperative ejection fraction was $33 \%$ at 90 months of follow up the ejection fraction was $58 \%$. The patient at 90 months was asymptomatic. Of the idiopathic heart disease group, nine patients underwent median sternotomy, and received human fetal stem cells (HFDSCs from ectopic pregnancy or spontaneous abortion, three patients received autologous bone marrow stem cells ABMSC) and 1HFDSCs for Minimally Invasive Surgery.

Patients with HFDSC, compared to baseline, improved: The mean ( \pm SD) NYHA class decreased from 3.4 \pm 0.5 to $1.33 \pm 0.5$ ( $P=0.001$ ); Mean EF increased $31 \%$, from $26.6 \% \pm 4.0 \%$ to $34.8 \% \pm 7.2 \%(p=0.005)$; the yield in ETT increased $291.3 \%$, from 4.25 minutes to 16.63 minutes (128.9\% in metabolic equivalents, 2.45 to 5.63) $(P<0.0001)$; the mean LVEDD decreased $15 \%$, from $6.85 \pm 0.6 \mathrm{~cm}$ to $5.80 \pm 0.58 \mathrm{~cm}(P<0.001)$; the mean performance on the 6-minute walk test increased $43.2 \%$, from $251 \pm 113.1$ seconds to $360 \pm 0$ seconds $(P=0.01)$; the mean distance increased $64.4 \%$, from $284.4 \pm 144.9 \mathrm{~m}$ to $468.2 \pm 89.8 \mathrm{~m}(\mathrm{P}=0.004)$; and the mean score in the Minnesota congestive HF test decreased from $71 \pm 27.3$ to $6 \pm 5.9(p<0.001)$. Kaplan-Maier's probability of survival at 40 months was $66 \%$. No rejection or cancer was observed at follow-up, in this series follow-up was discontinued at 4 years. In idiopathic patients receiving autologous cells by Mininvasive technique preoperative NYHA was $3.6(+/-0.70) 6$ months after receiving stem cell therapy. The mean value of the functional class was $1.9(+/-0.90)(p<0.005)$. ) showing marked clinical improvement. The preimplantation ejection fraction was $28 \%$ $(+/-3.6 \%)$ and at 6 months $44 \%(+/-4.7 \%)(p<0.005)$. There was a similar change in ventricular diameters: After 6 months LVESV went from $50 \mathrm{~mm}(+/-3.3)$ to $42 \mathrm{~mm}(+/-4.5)(\mathrm{p}<0.05)$. Two of the three patients in this group received re-synchronization therapy; one died at 10 years and 4 months, another at age 11 and another one alive at 12 years of the implant. More experience should be performed with different techniques and cells to find the appropriate treatment in this type of patients.

\section{Introduction}

Congestive heart failure is one of the main causes of cardiac morbidity and mortality in the 21st century [1,2]. Patients in advanced stages (NYHA Functional Class III/IV) have a 5 -year survival rate below $50 \%$, with a $40-50 \%$ mortality rate [3], with high rates of re-hospitalization, morbidity and complications, and high costs associated with health services. The etiology of dilated cardiomyopathy is $60 \%$ due to ischemic cardiomyopathy and $40 \%$ of idiopathic no ischemic origin. 
This category of patients has been managed until now with medical treatment (ACE inhibitors, diuretics, beta-blockers, and Spirolactone), ventricular re-synchronization, ventricular assist and cardiac transplantation. Cardiac transplantation is the surgical treatment of choice for patients with advanced heart failure. This procedure has been successful in many countries; however, there are many limitations, the most important being the shortage of donors and the contraindications of old age and serious comorbid situations [4]. In addition, there have been frequent deaths during prolonged periods on the waiting list for organ reception.

The final stage of several heart diseases that end in congestive heart failure is due to the quantitative deficiency of cardiomyocytes and cardiac remodeling [5]. The goal of cell therapy is the restocking of the myocardium with cells capable of restoring contractility and blood flow: this will improve the systolic function of the heart. The introduced cells must have the ability to differentiate into cardiomyocytes or promote revascularization based on angiogenesis.

Several studies have shown that adult bone marrow is a rich reservoir of these mesenchymal pluripotent stem cells, which contribute to functional neoangiogenesis. They also participate in wound healing and reversal of lower limb ischemia [6], postMI neoangiogenesis [7,8], endothelialization of vascular grafts [9], atherosclerosis [10], retinal and lymphoid neo-vascularization [11] and vascularization during neonatal development [12]. The first experiences and most of the cellular therapy administered to patients with Heart Failure so far has been with stem cells derived from the bone marrow $[7,8]$. Hyperbaric oxygen therapy may increase the circulation of CD34-CD45 and eventually create angiogenesis [13]. Embryofetal cells (HFDSCs) are more pluripotent than adult stem cells [14], and work has been performed on spinal cord injuries [15], cerebrovascular accident [16], other neurological and neurological disorders Eye disorders [17] and diabetes [18], there have been no reported cases of HFDSC use in Cardiac Failure therapy except our experience [19].

\section{Methods}

All protocols and treatments were performed with the authorization of the hospital authorities and the ethics council of each center; Patients authorized intervention and publication by signing informed consent. Patients presented ischemic or idiopathic cardiomyopathy with a severe decrease in LVEF and severe class III / IV heart failure. Between 2003 and 2011, 17 patients with heart failure were treated with stem cells by our Foundation. 4 with ischemic cardiomyopathy 3 were implanted with autologous bone marrow (ABMSC) plus bypass surgery. One with hyperbaric medicine plus bypass surgery 13 with idiopathic cardiomyopathy were implanted surgically with 2 different types of stem cells. 10 patients were implanted with stem cells derived from human fetuses (HFDSCs) and 3 patients with autologous bone marrow stem cells (ABMSC).

\section{The inclusion criteria were:}

1. Patients in NYHA functional class III / IV.

2. Ischemic or idiopathic cardiomyopathy with LVEF $<35 \%$.

3. Optimal medical therapy, including ACE inhibitors, spironolactone, beta-blockers and diuretics, averaging $85 \%$ of the maximum dose.

4. Symptomatic condition despite the optimal pharmacological treatment for Heart Failure.

\section{His exclusion criteria were:}

1. Decompensated congestive heart failure in the last 6 days.

2. Cancer present during the last 5 years. 
3. Presence of hematological diseases.

4. Leukocyte count above 12,000 / cc or below 5000 / CC.

5. Renal insufficiency requiring hemodialysis.

6. Previous heart surgery.

7. Valvular heart disease requiring surgery.

8. Preoperative steroid treatment.

9. Infectious diseases.

10. Blood disease.

11. Diagnosis of epilepsy

12. Positivity in the Human Immunodeficiency Virus or in the Venereal Disease Test.

13. Intolerance or hypersensitivity to biological substances.

14. Participation in another clinical trial.

15. Have a history of drug or alcohol abuse.

16. Psychiatric disorders.

17. Suicide attempts in the previous 2 years.

18. Pulmonary thromboembolism in the last 6 months.

19. Mechanical ventilation support in the last 10 days.

20. Morbid obesity.

Patients who were initially included but who did not comply with the protocol (testing or treatment), were lost at follow-up, or developed a new unrelated disease were excluded from the study. For each patient, preoperative medications (digoxin, furosemide, spironolactone, angiotensin converting enzyme inhibitors, angiotensin receptor blockers, beta-blockers) were maintained during the study and follow-up.

\section{Extraction and treatment of autologous stem cells}

Bone marrow stem cells: The patients were taken to the Operations Room monitored, anesthetized and placed in the prone position. Bone marrow was collected by hematologists from the iliac crest team, as is usually done in hematology and hemotherapy departments: Bilaterally between the two posterior spines. Using this technique we were able to harvest from 500 to $600 \mathrm{ml}$ of bone marrow with a minimum number of puncture sites and placed in a special vessel with $10000 \mathrm{U}$ of heparin and acetylsalicylate lysine to prevent coagulation. At least $250 \mathrm{ml}$ of bone marrow must be harvested to continue the protocol. His bone marrow was filtered followed by a 200 $\mu \mathrm{m}$ filter. The resulting solution was centrifuged at $400 \mathrm{~g}$ for $15 \mathrm{~min}$. The cell pellet was resuspended in phosphate buffered saline (PBS). The cell solution was mixed 3:1 with a $155 \mathrm{mmol} / \mathrm{L} \mathrm{NH} 4 \mathrm{Cl}$ solution and $0.1 \mathrm{mmol} / \mathrm{L}$ EDTA and adjusted for 15 minutes at room temperature. The solution was then centrifuged at $400 \mathrm{~g}$ for $10 \mathrm{~min}$. The pellet was washed with PBS and resuspended. The cell suspension was placed on Ficoll-Paque (1.077 density) 4:1 and centrifuged at $400 \mathrm{~g}$ for $30 \mathrm{~min}$. The upper layer was aspirated, leaving the mononuclear cell layer at the interface. The interphase cell was transferred to a new conical tube with PBS and centrifuged at $300 \mathrm{~g}$ for $10 \mathrm{~min}$. The supernatant was removed, and the cell pellet was resuspended in PBS. Cell counts 
were performed and magnetic labeling was performed with Isolex 300i according to standard protocol for peripheral blood progenitor cell products to obtain an enriched product of at least $70 \%$ CD34+cells. The resulting cell solution was resuspended in $30 \mathrm{cc}$ of the patient's own serum and 10,000 $\mathrm{U}$ of heparin sulfate. Cell viability was established with a standard Trypan blue exclusion.

Stem cells derived from human fetuses: Stem cells were provided by The Institute for Regenerative Medicine in Barbados, and were processed and prepared by the Institute for Problems of Cryobiology and Cryomedicine (IPCC) (Kharkov, Ukraine). The IPCC obtains HFDSCs from fetuses 5 to 12 weeks' gestation of legal consent, unpaid donors who have undergone terminated ectopic pregnancies, elective abortions or spontaneous miscarriages. HFDSCs are prepared. From fetal liver tissue harvested under sterile conditions and subjected to polymerase chain reaction tests for human immunodeficiency virus, hepatitis B and C, mycoplasma, toxoplasmosis, cytomegalovirus, herpes simplex virus I and II, rubella and Treponema pallidum; HFDSCs were also cultured for bacterial and fungal contamination.

Cell preparations were stored in cryo preservatives at $-196^{\circ} \mathrm{C}$ in liquid nitrogen. The percentage of viable cells before thawing was $60 \%$ as per IPCC certification. The IPCC sent HFDSCs in minishift containers in cryo preserved state $\left(-150^{\circ} \mathrm{C}\right.$ to $\left.-196^{\circ} \mathrm{C}\right)$ to the Luis Vernaza Hospital in Guayaquil Ecuador for this study, and they remained in this state until its use. Just before the procedure, the HFDSCs were thawed at room temperature. In 9 patients, the cells were diluted in $80 \mathrm{ml}$ of saline solution at $37^{\circ} \mathrm{C}$; In 1 patient, who underwent the procedure by minithoracotomy procedure, the cells were diluted in $15 \mathrm{ml}$. Patients received $7.5 \times 105$ cells / ml and $5.3 \times 106$ cells $/ \mathrm{ml}$, respectively. So in total they received between 60-80x106 HFDSCs.

\section{Surgical technique}

Esternotomy: In 3 patients, coronary artery bypass surgery was performed by sternotomy (OPCAB), and the autologous stem cells of the same patient were injected into different areas of the left ventricle $1 \mathrm{ml}$ to $3 \mathrm{~mm}$ deep (ABMSC). The amount was variable in each patient. In a patient after 18 sections of 1 hour of hyperbaric chamber treatment at $1.4 \mathrm{AT}$, angiogenesis was generated and at one year 2 coronary grafts were connected to the anterior descending artery and Diagonal (D) with the left internal mammary artery and a saphenous vein, Embryofetal stem cells (HFDSCs) were injected into 9 patients. Thirty marks (a1 $\mathrm{cm}$ distance) were made with a methylene blue marker on the anterolateral, posterolateral and diaphragmatic walls of the left ventricle and on the anterolateral wall of the right ventricle, avoiding coronary blood vessels. 80 injections of $1 \mathrm{ml}$ each were given in the marked areas. The injections were made $3 \mathrm{~mm}$ deep with a 25 gauge needle and a catheter (Figure 1). During the procedure, blood pressure, central venous pressure, urinary flow, electrocardiogram,

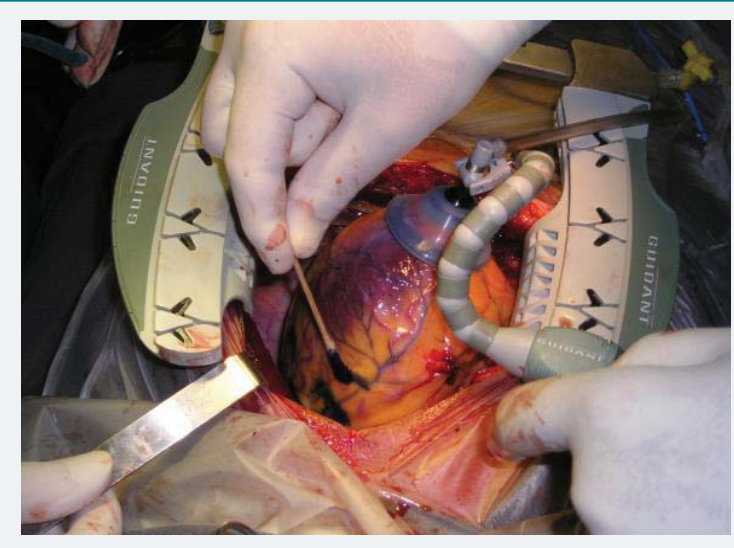

Figure 1: Blue sternotomy marker for 80 injections. 
oxygen saturation and the final concentration of carbon dioxide in the exhaled air were monitored. Infusions of potassium $(20 \mathrm{mEq} / \mathrm{hr})$ and magnesium $(1 \mathrm{~g} / \mathrm{hr})$ were initiated before the operations and were maintained until the time of chest closure. All patients were extubated in the operating room.

Minimally Invasive: 3 patients received autologous bone marrow stem cells and 1 cells derived from human fetuses.

After collection of BM precursors in cases of autologous cells, the patient was placed in a right lateral position with an inclination of $30^{\circ}$ to $45^{\circ}$ from the horizontal plane of the right hemithorax.

The video-assisted surgery includes the positioning of three $10 \mathrm{~mm}$ trocars in the intercostal spaces 3, 5 and 7: one for the camera and the remnants for the instruments. We use a double-lumen oro-tracheal tube in this procedure and the trocars are inserted once the left lung has been isolated. The camera is then inserted into the seventh space (Figure 2).

Exploration begins by opening the pericardium anteriorly to the position of the nerve nerve. Injection is performed in the selected areas, guided by preoperative echocardiography and avoiding intraventricular and intracoronary injection. We delivered $1 \mathrm{cc}$ aliquots separated by 2 to $3 \mathrm{~cm}$ and 3 to $5 \mathrm{~mm}$ depth with a $25 \mathrm{G}$ needle with an average of 25 injections in the ABMSC (Figure 3). Only 15 injections were performed on the anterolateral wall in the patient who underwent HFDSC with the same technique. The procedure was completed when the trocars were removed and the thoracic tube was placed. All 4 patients were extubated in the operating room. The results of these studies were analyzed by independent cardiologists, not involved in them.

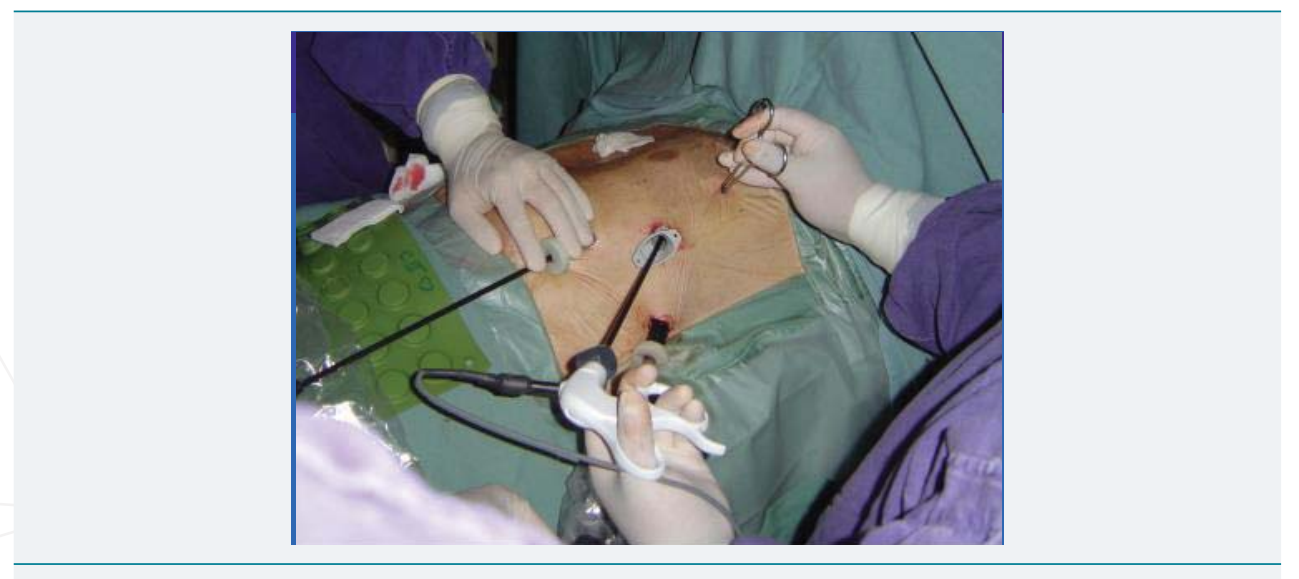

Figure 2: Minimally invasive approach for implantation of stem cells.

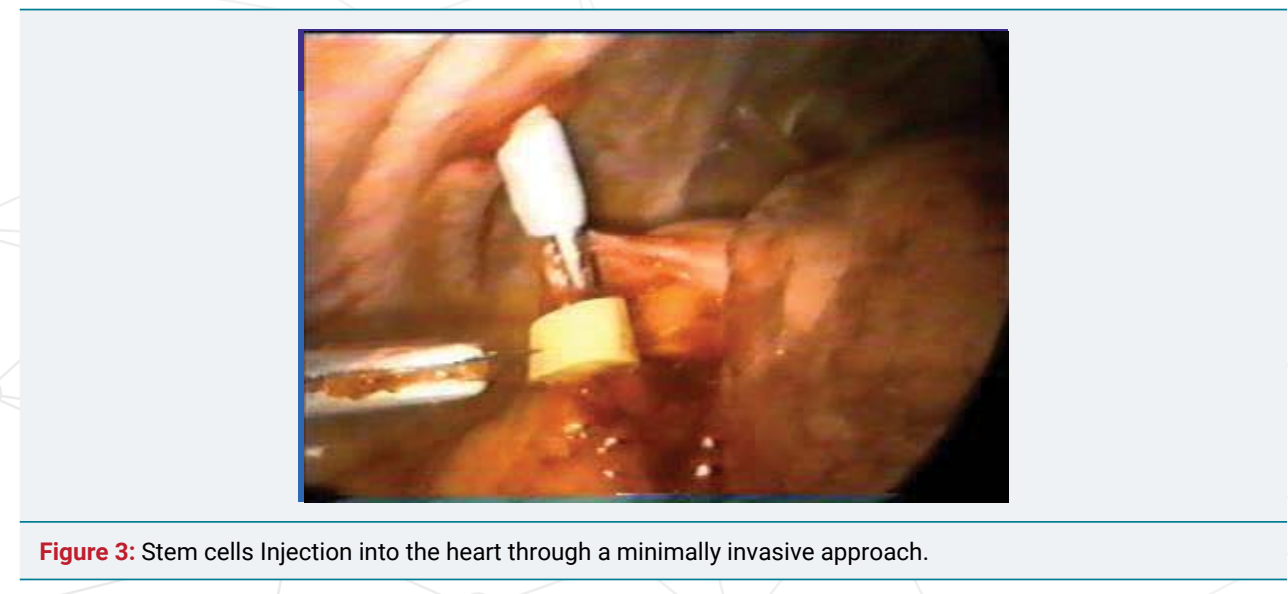




\section{Results}

In the bone marrow stem cell group plus coronary bypass. The ejection fractions of the coronary artery bypass graft group Off Pump OPCAB (control group) versus coronary artery bypass graft Off Pump OPCAB plus stem cell transplantation were as follows: preoperative, $30.7 \%+/-2.5 \%$ compared to $29.4 \%+/-3.6 \%$; 1 month, $36.4 \%$ +/- $2.6 \%$ versus $42.1 \%+/-3.5 \%$; 3 months, $36.5 \%+/-3.0 \%$ vs. $45.5 \%+/-2.2 \%$; And 6 months, $37.2 \%+/-3.4 \%$ versus $46.1 \%+/-1.9 \%(p<0.001)[20,21]$. The first patient performed at our center in Argentina in this series is alive and asymptomatic 15 years after implantation, of the rest of this series we do not have current data

Three patients, two men and one woman with idiopathic cardiomyopathy (age range 62-71 average 67.6 years), of the heart failure unit met the inclusion criteria and received autologous stem cells by minimally invasive technique.

All patients were extubated in the operating room. The pleural tube was removed after 24 hours and discharged after an average of 2.26 days. No major complications were observed. The baseline NYHA functional class was 3.4. (+-0.70) 6 months after receiving treatment with stem cells, the mean value of the functional class was $1.3,(+$ $-0.90)(\mathrm{p}<0.005)$ showing a marked clinical improvement. Pre-implantation was $28 \%$ $(+/-3.6 \%$ and at 6 months $44 \%(+/-4.7 \%)(\mathrm{p}<0.005)$. There was a similar change in ventricular diameters: After 6 months the systolic volume $(\mathrm{p}<0.05)$. "Two of the three patients in this group received re-synchronization therapy at 99 and 127 months postimplant, one died at 120 months, another at 154 months and the other is alive at 160 months after the implant."

One patient was treated with a hyperbaric chamber after 18 sections of an average of one hour of 1.4 AT angiogenesis was created and the patient was operated on receiving 2 grafts without extracorporeal circulation. The preoperative ejection fraction was $30 \%$ at 90 months follow up the ejection fraction was $58 \%$ the patient is alive and asymptomatic at 90 months. In the embryofetal stem cell group; six women and four men (age range, 47-77 average 58 years) met the inclusion criteria and participated in the study. Nine of those who received HFDSCs by sternotomy and one by minimally invasive technique. There was no operative or perioperative mortality.

One male patient (U.J., 69 years) experienced a single transient ventricular fibrillation during the procedure but before receiving the injections; ventricular fibrillation was terminated by electrical cardioversion. One man (M.J., 66 years old) and one woman (V.M., 77 years old) required transient pacing in the postoperative period due to severe bradycardia $(<40 \mathrm{bpm})$, for 24 hours and 48 hours, respectively. One patient received dobutamine for 24 hours. He also had a mild pericardial effusion at 3 weeks, which resolved spontaneously. Later he was excluded from the protocol for noncompliance (he abandoned his controls), and in the end he died at 5 months.

Autopsy of the heart showed cardiomyocyte nests between the fibrotic tissue (Figure 4), but it was not possible to determine whether it was new growth myocardium or the remaining native fibers. One patient died at 18 months due to complications of diabetes. Another patient died suddenly at 8 months due to severe complications of gastroenteritis. The female patient who underwent her procedure through a minimally invasive technique died at 12 months of HF due to mitral insufficiency. She had rejected a mitral valve operation. Patients from HFDSCs who provided 40 months of follow-up data demonstrated improvements both clinically and in imaging studies. With respect to imaging studies, a greater wall thickness was observed, both eccentric and concentric.

Patients improved in association with increased contractility in these regions. In 4 of the patients in this group left ventricular contraction returned to normality assessed by echocardiography at 90 days (Figures 5-7). Compared with the baseline evaluations, we observed other improvements: The mean $( \pm$ SD) NYHA class decreased from $3.4 \pm 0.5$ to 


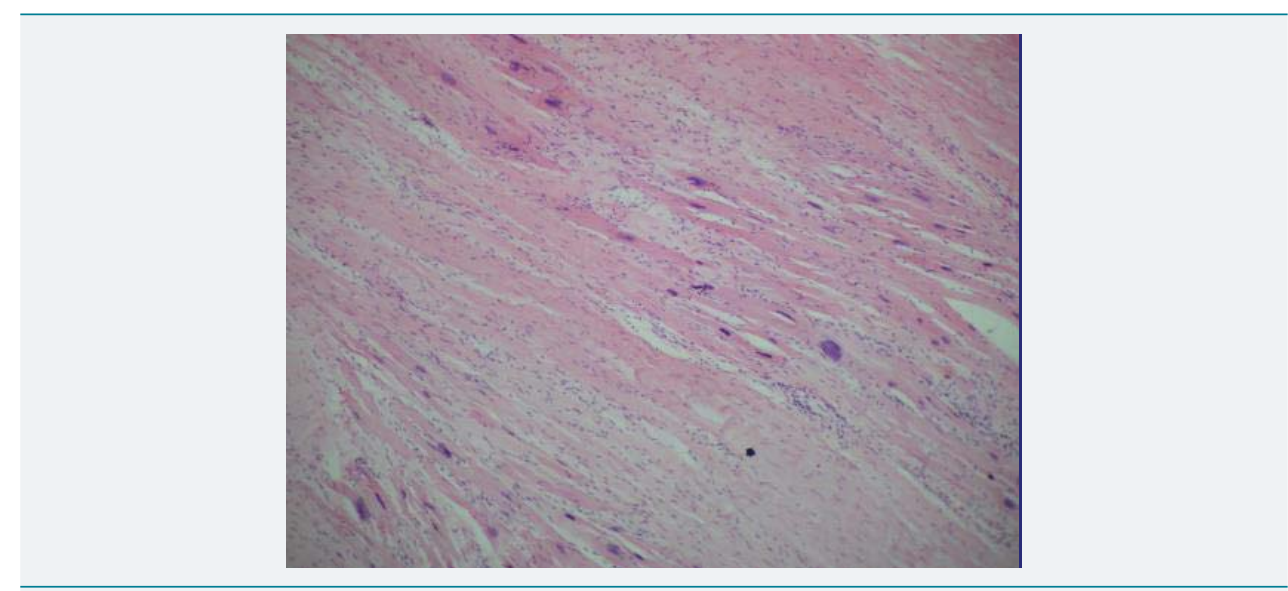

Figure 4: Autopsy of the heart showed nits of cardiomyocytes between the fibrocyte tissues.

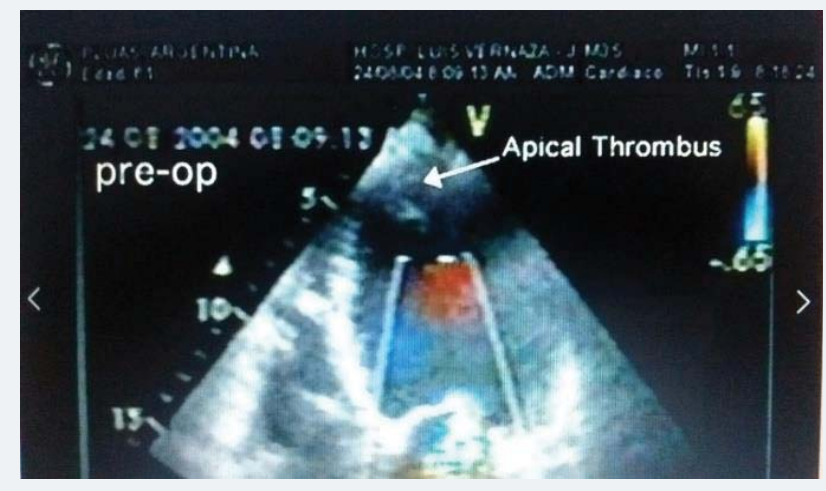

Figure 5: Echocardiogram Pre-injection of Embryofetal Cells.

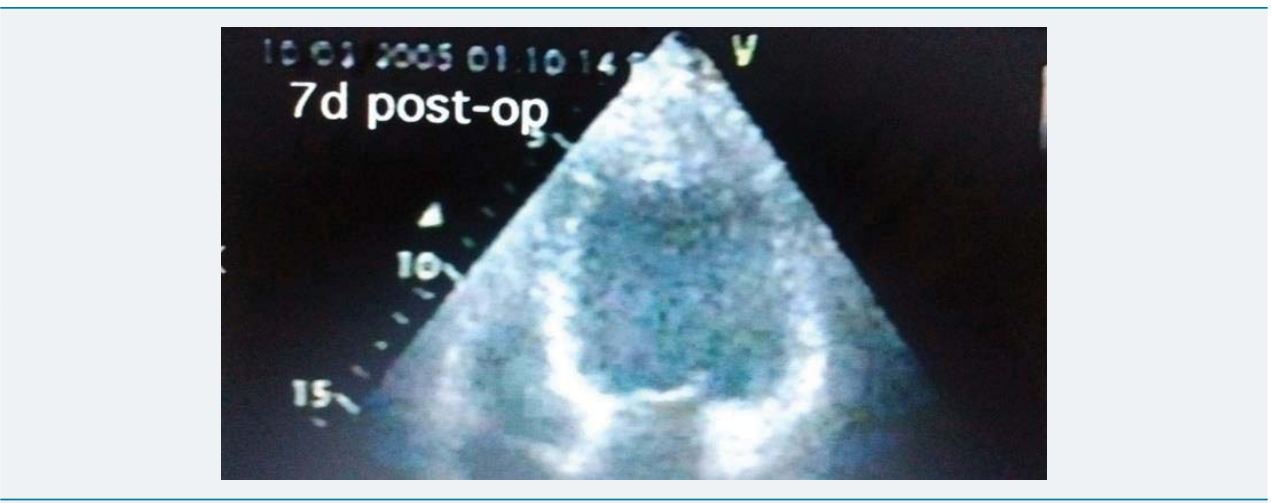

Figure 6: Septum stopped by embryofetal cell growth at 7 days after implantation.

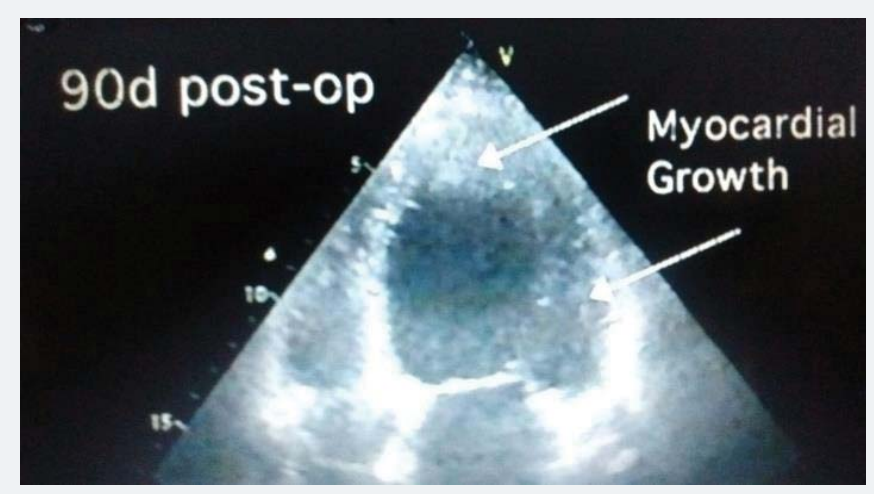

Figure 7: Normal ventricle at 90 days of implantation of embryofetal cells. 
$1.33 \pm 0.5(\mathrm{P}=0.001)$; Mean EF increased $31 \%$, from $26.6 \% \pm 4.0 \%$ to $34.8 \% \pm 7.2 \%$ (p $=0.005)$; The ETT yield increased $291.3 \%$, from 4.25 minutes to 16.63 minutes $(128.9 \%$ in metabolic equivalents, 2.45 to 5.63) ( $\mathrm{P}<0.0001)$; the mean LVEDD decreased $15 \%$, from $6.85 \pm 0.6 \mathrm{~cm}$ to $5.80 \pm 0.58 \mathrm{~cm}(\mathrm{P}<.001)$; the mean performance on the 6 -minute walk test increased $43.2 \%$, from $251 \pm 113.1$ seconds to $360 \pm 0$ seconds $(\mathrm{P}=0.01)$; The mean distance increased $64.4 \%$, from $284.4 \pm 144.9 \mathrm{~m}$ to $468.2 \pm 89.8 \mathrm{~m}(\mathrm{P}=0.004)$; and the mean score in the Minnesota congestive HF test decreased from $71 \pm 27.3$ to $6 \pm 5.9$ ( $p<0.001$ ). The probability of Kaplan-Maier survival at 40 months was $66 \%$.

No rejection was observed in these patients nor did malignancy develop nodules or cancer at follow-up. At 4 years, follow-up was discontinued with 66\% survival (K-M).

\section{Discussion}

Stem cell treatments depend not only on the type of cell to be used but also on the different implantation techniques. Intravascular cell injections are known to rapidly separate from the vessel. On the other hand, it is also well known that direct injection into the myocardium provides better coupling within the heart muscle. Therefore, whether in the case of HFDSC or ABMSC in our experience focused on direct approaches. When we have to deal with different stimuli, such as parietal stress or direct myocardial injury leading to hemodynamic overload, the heart responds with hypertrophy, able to initially compensate for loss of function. Later, and over a long subclinical period, progressive dilation continues to be compensated for by varying degrees of hypertrophy.

In the final stage, as described by Meerson et al. [22], dilatation overcomes hypertrophy and changes in cellular organization appear, such as: 1) myofibrillar lysis; 2) Increased lysosomes; 3) Distortion of the sarcoplasmic reticulum; 4) replacement of myocardial cells by fibrous tissue.

Simultaneously, capillary density and contractile reserve decrease, and diffuse myocyte necrosis is a characteristic of both idiopathic and ischemic dilated cardiomyopathy [23,24].

Therefore, idiopathic dilated cardiomyopathy can be described from a pathological point of view [25] as a dilated heart with hypertrophied walls; macroscopically the dilatation exceeds hypertrophy. Microscopically the heart is invaded by areas of interstitial and perivascular fibrosis, adjacent to necrotic areas and myocytes that may be atrophic or hypertrophic, with loss of the extracellular matrix. Cell therapy in these patients is directed at restoring and repopulating the myocardium, thus restoring lost function by supplying cells that are able to differentiate into myocardial cells.

The use of mesenchymal or stromal cells as precursors of non-hemopoietic tissues was first attempted by the German pathologist Conheim in 1867 [26]. It was later demonstrated in tissue cultures that they were able to form various tissues, such as bone, cartilage, muscle, ligaments, tendons, etc. [26,27], and to intervene in tissue repair [26]. An extremely interesting study showed that stromal stem cells treated with 5 Azacytidine a week formed interconnected with micro-tubulicardiomyocytes. After 2 weeks they begin to beat and this contraction becomes synchronous after three weeks develop natriuretic peptide and stained with antibodies against actin and myosin and have a potential for action of cardiac cells [28].

Trans-differentiation in the cardiac phenotype requires an adequate microenvironment. It depends on the cellular interconnection for the generation of cardiac transcription factors (GATA-4 and myocyte factor 2 that was also observed) [29]. This was also confirmed by other investigators, emphasizing the importance of intercellular integration of cardiomyocytes with trans-differentiated cells [30]. Among the various cell types studied, stromal stem cells were shown to have the ability to differentiate into muscle and vascular cells and produce angiogenesis. conducted by Weisel and Lee of the University of Toronto in 1999 [31]. 
This differentiation in the myogenic lineage with the development of actin, myosin and tropomyosin was demonstrated, as well as the presence of Conectin 43, a protein responsible for cellular interconnection.

Several mechanisms of action of stem cells have been proposed to improve cardiac function:

1. Fusion and transdifferentiation: Fusion with local cells has been ruled out, and the attractive concept of stem cells that trans-differentiate and cross the barrier has not yet been demonstrated. Perhaps the correct anatomical mechanism will be clarified when cell therapy can be used more as a bridge for heart transplantation and more biopsies can be performed to confirm the first observations.

2. Mobilization of cardiac stem cells: another theory proposes that implanted cells mobilize specific cardiac stem cells housed in the muscle that are capable of cardiac regeneration.

3. Angiogenesis: Implanted cells induce significant angiogenesis; according to some, this would be the main mechanism involved.

4. Extracellular Matrix: In heart failure there is a net loss of myocytes plus a loss of matrix architecture, leading to dilatation. The implanted cells could stabilize the latter, preventing dilation and balancing the enzymes of generation / degradation. This is the mechanism believed to cause Chagas disease [32].

The clinical application of this treatment began in 2000, and cases have increased worldwide. Our case studies show that this is a feasible procedure, which has no surgical or immediately postoperative mortality.

Our prospective, randomized study in ischemic patients showed marked improvement in the ventricular ejection fraction and in the functional class in which they received stem cells compared to those undergoing revascularization alone [20,21]. Treatment with hyperbaric oxygen opens a new possibility by stimulating the greater circulation of CD34-CD45 and eventually creating angiogenesis and allowing revascularization. The clinical benefits were evident in the improvement of the functional class, and no negative effects were observed in our initial experience.

Patients with idiopathic cardiomyopathy who received autologous cell therapy achieved a significant increase in LV ejection fraction immediately and improved clinical condition.

The findings from our initial experience clearly suggest that HFDSC transplantation improved cardiac function in patients with heartfailure due to idiopathic cardiomyopathy and also decreased left ventricular diastolic diameter with evidence of echocardiography in some of the new cell generation patients (Figures 5-7) No rejection or malignancy reactions were observed in this group at 40 months [19].

We believe it is imperative and extremely important that more research and trials with different techniques and stem cells of all kinds or with the stimulation of the own ones are carried out in patients with heart failure to be able to determine the most appropriate treatment in this type of patients.

\section{Conclusion}

It is clear that there are different alternatives and cells to treat patients with Heart Failure The Hyperbaric Oxygen Chamber producing angiogenesis open up a possibility for inoperable patients for an adjuvant treatment. The implantation of bone marrow cells plus a coronary bypass is another option for patients with ischemic cardiomyopathy. Embryofetal cells with limitations that go beyond medical science 
are according to observations commensurate with the unique experience we perform in humans that would produce new cardiac cells. More experience is needed to have definitive conclusion in terms of type of cells, and procedure to be able to determine the most appropriate treatment in patients with Heart Failure.

Statistical analysis applied to the study test (SPSS program), with $\mathrm{p}<0.05$ was considered significant.

\section{References}

1. Remme WJ, Swedberg K. Task force for the diagnosis and treatment of chronic heart failure, European Society of Cardiology. Guidelines for the diagnosis and treatment of chronic heart failure. European Heart Journal. 2001; 22: 1527-1560. Ref.: https://goo.gl/ENjTdx

2. Colucci W, Braunwald E. Pathophysiology of Heart Failure, en Heart Disease de Braunwald. 5a Edition. 1997; 360-393.

3. Enrique V, Carbajal MD, Prakas. Current Diagnosis and Treatment is Cardiology 2 nd Ed. Congestive Heart Failure. 2003.

4. Bolling SF, Pagani FD, Deeb GM. Intermediate-term outcome of mitral reconstruction in cardiomyopathy. J Thorac Cardiovasc Surg. 1998; 115: 381-386. Ref.: https://goo.gl/NiiBfR

5. Wang JS, Shum D, Galipeau J. Marrow stromal cells for cellular cardiomyoplasty: feasibility and potential clinical advantages. J Thorac Cardiovasc Surg. 2000; 120: 999-1006. Ref.: https://goo.gl/1tNxfM

6. Rafii S, Lyden $\mathrm{D}$. Therapeutic stem and progenitor cell transplantation for organ vascularization and regeneration. Nat Med. 2003; 9: 702-712. Ref.: https://goo.gl/8D8Qqc

7. Orlic D, Kassutra J, Chimenti S, Jakoniuk I, Anderson SM, et al. Bone marrow cells regenerate infracted myocardium. Nature. 2001; 410: 701-705. Ref.: https://goo.gl/VDLjv3

8. Edelberg JM, Tang L, Hattori K, Lyden D, Rafii S. Young adult bone marrow-derived endothelia precursor cells restore aging-impaired cardiac angiogenic function. Circ Res. 2002; 90: E89-E93. Ref.: https://goo.gl/2dmhJe

9. Shi Q, Rafi S, Wu MH, Wijelath ES, Yu C, et al. Evidence for circulating bone marrow-derived endothelial cells. Blood. 1998; 92: 362-367. Ref.: https://goo.gl/z2fWF3

10. Sata M, Saiura A, Kunisato A, Tojo A, Okada S, et al. Hematopoietic stem cells differentiate into vascular cells that participate in the pathogenesis of atherosclerosis. Nat Med. 2002; 8: 403-409. Ref.: https://goo.gl/HnCjtL

11. Otani $A$, Kinder $K$, Ewalt $K$, Otero FJ, Schimmel $P$, et al. Bone marrow derived stem cells target retinal astrocytes and can promote or inhibit retinal angiogenesis. Nat Med. 2002; 8: 1004-1010. Ref.: https://goo.gl/sJ98ME

12. Young PP, Hofling AA, Sands MS. VEGF increases engraftment of bone marrow-derived endothelial progenitor cells (EPCs) into vasculalture of newborn murine recipients. Proc Natl Acad Sci USA. 2002; 99: 11951-11956. Ref.: https://goo.gl/TLhwpp

13. Heyboer M, Milovanova TN, Wojcik S, Grant W, Chin M, et al. CD34+/CD45-dim stem cell mobilization by hyperbaric oxygen - changes with oxygen dosage. Stem Cell Res. 2014; 12: 638-645. Ref.: https://goo.gl/stqQak

14. O’Donoghue K, Fisk NM. Fetal stem cells. Best Pract Res Clin Obstet Gynaecol. 2004; 18: 853-875. Ref.: https://goo.gl/WFgYr9

15. Tsymbalyuk VI, Yaminsky YY. Usage of embryonic nerve tissue transplantation to improve the conductivity of spinal cord after traumatic damage in animals and humans. Transplantology. 2003; 4: 199-201.

16. Zorin MO, Yurchenko TN, Latyshev DY. 2003. Application of cryopreserved suspension of embryonic neural cells in combined treatment of patients with ischemic insults of basal ganglias. Transplantology 4: 149-50.

17. Salogub TV. Perspective of embryonic cell transplantation when treating patientswthepileptiform neuralgia of peripheric genesis. Transplantology. 2003; 4: 184-185. Ref.: https://goo.gl/BKqVuR

18. Grischenko VI, Bobirova LE, DvornekIL,y col. 2003. Use of biotechnology in treatment of type I dabetes. Transplantology 4: 16-19. 
19. Benetti F, Penherrera E, Maldonado T, Vera YD, Subramanian V, et al. Direct Myocardial Implantation of Human Fetal Stem Cells in Heart Failure Patients: Long-term Results. Heart Surg Forum. 2010; 13: Ref.: https://goo.gl/FdnVfw

20. Benetti F, Viña RF, Patel AN. OPCABG plus simultaneous autologus stem cells implants TCTMD. com. june 2003.

21. Patel AN, Geffner L, Vina RF, Saslavsky J, Kormos R, et al. Surgical treatment for congestive heart failure with autologous adult stem cell transplantation: A prospective randomized study: $J$ Thorac Cardiovasc Surg. 2005; 130: 1631-1638. Ref.: https://goo.gl/XTr3sq

22. Meerson FZ. The myocardium in hyperfunction, hypertrophy and heart failure. Circ Res. 1969; 25: 1-163 Ref.: https://goo.gl/ebUrEX

23. Zak R. Cardiac hipertrophy: biochemical and cellular relationships. Hosp Pract. 2016; 18: 85-97. Ref.: https://goo.gl/3rKRxD

24. Prosper F, Pérez A, Merino J. Adult stem cells for myocardial repair. Basic ApplMyol 13: 15-22,2003.

25. Colucci WS, Braunwald E. Patophisiology of heart failure in Braunwald"s Heart Disease 5th edition Saunders company 1997.

26. Prockop DJ. Marrow Stromal cells as Stem Cells for nonhematopoietic tissues. Science. 1997; 276: 71-74. Ref.: https://goo.gl/m4UcND

27. Pittenger MF, Mackay AM, Beck SC, Jaiswal RK, Douglas R, et al. Multilineage potential of adult human mesenchymal stem cells. Science. 1999; 284: 143-147. Ref.: https://goo.gl/UcXFMi

28. Makino S, Fukuda K, Miyoshi S, Konishi F, Kodama H, et al. Cardiomyocites can be generated from marrow stromal cells in vitro. J Clin Invest. 1999; 103: 697-705. Ref.: https://goo.gl/N4GYGu

29. Xu M, Wani M, Dai YS, Wang J, Yan M, et al. Differentiation of bone marrow stromal cells into cardiac phenotype requires intracellular communication with myocites. Circulation 2004; 110: 2658-2665. Ref.: https://goo.gl/kQKnXu

30. Chedrawy EG, Wang JS, Nguyen DM, Shum-Tim D, Chiu R. Incorporation and integration of implanted myogenic and stem cells into native myocardial fibres: anatomic basis for functional improvements. J Thorac Cardiovasc Surg. 2002; 124: 584-590. Ref.: https://goo.gl/wnW8fH

31. Pittenger MF, Martin BJ. Mesenchymal stem cells and their potential as cardiac therapeutics. Circulation research. 2004; 95: 9-20. Ref.: https://goo.gl/MQHvLH

32. Vilas-Boas F, Feitosa GS, Soares MB, Pinho-Filho JA, Mota A, et al. Bone marrow cell transplantation to the myocardium of a patient with heart failure due to Chagas disease. Arg Bras Cardiol. 2004; 82: 181-184. Ref.: https://goo.gl/72WixZ 